\begin{tabular}{|c|c|c|c|c|c|c|c|c|}
\hline \multirow[b]{2}{*}{ Case No } & \multirow[b]{2}{*}{ Age (years) } & \multirow{2}{*}{$\begin{array}{l}\text { Time from start of } \\
\text { nebulisers to onset of } \\
\text { ocular symptoms }\end{array}$} & \multicolumn{2}{|c|}{ Visual acuity on referral ${ }^{\star}$} & \multirow{2}{*}{$\begin{array}{c}\text { Intraocular pressure } \\
\text { on referral } \\
(\mathrm{mm} \mathrm{Hg}(\mathrm{kPa}))\end{array}$} & \multirow{2}{*}{$\begin{array}{l}\text { Delay to referral } \\
\text { (hours) }\end{array}$} & \multicolumn{2}{|c|}{ Final visual acuity ${ }^{\star}$} \\
\hline & & & Right eye & Left eye & & & Right eye & Left eye \\
\hline 1 & 68 & $24 \mathrm{~h}$ & $6 / 24 \dagger$ & Count fingers $\dagger$ & $\begin{array}{l}60(8 \cdot 0) \\
52(6 \cdot 9)\end{array}$ & 24 & $6 / 9$ & $6 / 9$ \\
\hline 2 & 67 & $1 \mathrm{~h}$ & Count fingers $\dagger$ & $6 / 9$ & $\begin{array}{l}64(8 \cdot 5) \\
22(2 \cdot 9)\end{array}$ & 72 & $6 / 36$ & $6 / 9$ \\
\hline 3 & 69 & $36 \mathrm{~h}$ & $6 / 60 \dagger$ & $6 / 6$ & $\begin{array}{l}45(6 \cdot 0) \\
29(3 \cdot 9)\end{array}$ & $72^{\circ}$ & $6 / 36$ & $6 / 6$ \\
\hline 4 & 70 & $24 \mathrm{~h}$ & $\begin{array}{l}\text { Hand } \\
\text { movement }\end{array}$ & $\begin{array}{c}\text { Hand } \\
\text { movement }\end{array}$ & $\begin{array}{l}55(7 \cdot 3) \\
48(6 \cdot 4)\end{array}$ & 24 & $\begin{array}{c}\text { Hand } \\
\text { movement }\end{array}$ & $6 / 24$ \\
\hline 5 & 78 & 9 days & $6 / 36 \dagger$ & $6 / 36 t$ & $\begin{array}{l}60(8 \cdot 0) \\
48(6 \cdot 4)\end{array}$ & None & $6 / 12$ & $6 / 9$ \\
\hline
\end{tabular}

^Measured by Snellen's test.

† Eye with acute angle closure glaucoma

cholinergic activity (for example, amitriptyline in case 3) may aggravate the problem.

No cases of acute angle closure glaucoma have been reported with inhaled ipratropium or salbutamol. The higher doses achieved by nebulised administration and the fact that the drugs may escape around the mask and enter the eye probably account for their ability to cause acute angle closure glaucoma when administered with a nebuliser. A study on patients with chronic bronchitis showed that when ipratropium bromide and salbutamol were administered simultaneously with a nebuliser intraocular pressure increased in all patients with narrow drainage angles. ${ }^{3}$ Transient angle closure occurred in half of these patients, although none required ophthalmic intervention. The use of goggles prevented the rise in intraocular pressure during nebulised administration of these drugs.

We suggest the following precautions to try to avoid acute angle closure glaucoma. Patients anatomically predisposed to the condition should be identified (those with shallow anterior chambers by the flashlight test,${ }^{+}$or with severe hypermetropia). It is also important to exclude a history of abortive angle closure glaucoma with symptoms of blurred vision and haloes around lights associated with ocular or periorbital pain. Abortive acute angle closure glaucoma may be precipitated in a darkened room or when in a prone or semiprone position (for example, when reading) and may be aborted by going to sleep. When administering drugs the mask must be correctly placed to avoid aerosols and droplets spreading from around the mask into the patient's eyes. If possible try to avoid simultaneous administration of nebulised ipratropium and salbutamol. Any topical antiglaucoma treatment should be continued during the patient's admission to hospital. If acute angle closure glaucoma is suspected the patient must be referred to an ophthalmologist immediately.

1 Packe GE, Cayton RM, Mashhoudi N. Nebulised ipratropium bromide and salbutamol causing closed-angle glaucoma. Lancet 1984;ii:691.

2 Malani JT, Robinson GM, Seneviratne EL. Ipratropium bromide induced (an

3 Kalra $L$, Bone $M$. The effect of nebulised bronchodilator therapy on intraocular pressure in patients with glaucoma. Chest 1988;93:739-41.

4 Gray RH, Doran RM. Pupil dilatation: a neglected procedure? Hospital Update 1990;16:446-52.

(Accepted 25 November 1991)

\title{
Medicine in Europe
}

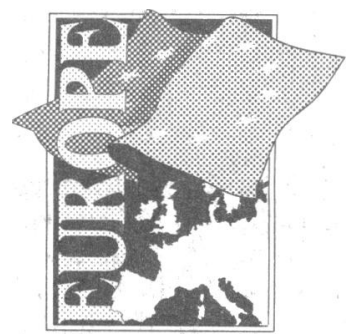

This is the fifth in a series of articles looking at medical issues in Europe.

\section{Chantry Road,} Birmingham B13 8DJ

Stephen Brearley, FRCS, United Kingdom representative, Permanent Working Group of European Funior Hospital Doctors

BMF 1992;304:41-4

\section{Medical education}

\author{
Stephen Brearley
}

One of the principal objectives of the Treaty of Rome was the establishment of free migration within the European Economic Community (now the European Communities (EC)). Free migration implies a right to live and to work in any member state. For this to be practical for professional people a mechanism had to be found to recognise professional qualifications granted in one country in all the others. The first group for whom such a mechanism was set up was doctors, but it took 18 years from the signing of the treaty to agree the medical directives, which provide the essential framework.

This delay was indicative of the diversity in medical training and qualifications which existed and still exists to a considerable extent in western Europe. Early negotiations on the directives sought to define precisely, in terms of duration and content, the training which doctors had to undergo if their qualifications were to be recognised throughout the community. An agreement of this nature proved impossible. It was the president of the European Commission, Ralf Dahrendorf, who cut the Gordian knot by declaring that, whatever their educational background, doctors throughout the community had similar skills and attributes and that, as the final product was the same, a qualification awarded by one member state should be regarded as satisfactory by all the others.

As a result the requirements of the directives, in terms of education leading to a basic medical qualification, are minimal (box). The directives have made free migration for doctors a reality but as a means of setting educational standards they have been a failure.

Mutual recognition of qualifications is a prerequisite for free migration because the titles attesting medical qualifications are legally protected in all EC states. Migrating doctors can practise only if their qualifications are recognised as giving them a right to that title. In many states the title medical specialist is also legally protected. This is a consequence of the reimbursement arrangements of social security systems, which differ for specialists and generalists. In order to enable specialists to migrate it was necessary for the directives to include provisions for the mutual recognition of specialist qualifications.

These provisions are almost as weak as those governing basic medical qualifications (box). In those countries where protected specialist titles exist the period of postgraduate training leading to them is normally between three and six years. This is reflected 
in the directives. Although the minimal standards of training required are comfortably exceeded in almost all EC states, they are probably not achieved in a minority.

There is widespread misunderstanding of the meaning of mutual recognition of specialist qualifications. The directives require each country to recognise the named qualifications in specialised medicine awarded in other member states: countries must give these named qualifications the same effect as they give to their own qualifications. This effect, where it exists, has to do with reimbursement arrangements under social security systems. Such a system does not exist in the United Kingdom, where the title of specialist is not legally protected. Consequently, there is no effect to be given to a specialist title carried by a doctor from elsewhere.

The United Kingdom specialist qualification listed in the directives is the certificate of specialist training which may be issued by the General Medical Council to appropriately trained British doctors who wish to work as specialists in other member states. Like all the other listed specialist qualifications it is without effect in the United Kingdom. Furthermore, fellowships and memberships of royal colleges, higher degrees, and certificates of accreditation are not among the qualifications listed in the directives and have no status elsewhere in the European Community.

\section{Basic medical training}

Luxemburg has no medical school. All the remaining countries claim to have a numerus clausus, or numerical limit on medical school places, but determine it in different ways. In Italy there is practically no restriction on entry to the course and there have been examples of as many as 2000 in a class. France exercises control by means of an examination at the end of the first year, with only $20 \%$ of students being admitted to the remainder of the course, and there is a process of continuous attrition in Belgium. All other countries exercise control at entry. The number of places is rarely related to expected demand for doctors and bears a variable relation to the educational capacity of the schools.

Where selection at entry is practised, school leaving grades are always an important criterion but various other factors may be taken into account. In Germany candidates accumulate additional points for the time they have been waiting for a place and for their assessment at interview. Spain has a national examination (selectividad), the results of which are combined with school grades. In the Netherlands there is a lottery which is weighted in favour of those with better school results.

In all countries the course lasts at least six years (the preregistration year in the United Kingdom is part of basic medical education), corresponding to the requirements of the directives (six years or 5500 hours of instruction). Generally, it is divided into preclinical and clinical components, but the proportions vary. The amount of laboratory work in the preclinical period varies and in countries with large medical school intakes it is virtually non-existent.

In many countries the clinical period is still largely theoretical and nowhere do students spend as much time in clinical areas as in the United Kingdom and the Republic of Ireland. Discussions with trainees from EC countries suggest that, typically, patient contact represents $20 \%$ of a student's time in Italy, three hours a day in Spain, four to six hours a week in Germany. In Belgium much clinical training is by means of patient demonstrations. In general, clinicians seem to show less interest in teaching students at the bedside than they do in the United Kingdom. Almost all
The 1975 medical directives require that training leading to a recognised qualification should ensure:

- Adequate knowledge of the sciences on which medicine is based

- Sufficient understanding of the structure, functions, and behaviour of healthy and sick persons

- Adequate knowledge of clinical disciplines and practices

- Suitable clinical experience in hospitals under appropriate supervision

Adequate, sufficient, suitable, and appropriate are not defined.

The 1975 medical directives require that training leading to a recognised specialist qualification must:

- Include practical and theoretical instruction

- Be a full time course, recognised by the competent authority*

- Be held in approved premises

- Involve personal participation by the trainee in the work of the establishment

- Last for a stipulated minimum duration.

$\star$ Provision for part time training was made in a 1982 directive.

countries confine teaching exclusively to university hospitals.

Most medical schools assess their students by in course examinations, frequently numerous. In some countries these are entirely theoretical (written or oral) and in most others testing of clinical skills plays only a small part.

Variability is at its greatest with regard to general clinical training (the preregistration year in the United Kingdom). A comparable period exists in the Republic of Ireland, Denmark, France, and, since 1988, in Germany. In other countries the last year of the medical course constitutes a form of internship but with much less responsibility than is borne by house officers in the United Kingdom. Greek doctors are required to complete one year of government service, usually in singlehanded practice providing care to rural communities, before being eligible to apply for specialist training.

\section{Specialist training}

In all countries the nature of specialist training reflects the form of the health service. In the United Kingdom, where specialist practice is conducted almost exclusively by consultants in the NHS, training is designed to produce individuals with the skills, knowledge, and experience necessary for appointment as a consultant. Most other European countries have a social security system, under which most specialists are in private practice outside hospitals, are approached directly by patients, provide a largely outpatient service, and recoup their fees through the system. Such an arrangement demands a means whereby the public and the social security system can identify a qualified specialist but it does not require a training as prolonged and exhaustive as is usual in the United Kingdom because the responsibilities of specialists are different. Qualification as a specialist does not indicate suitability for appointment to a senior hospital and is perhaps better compared with acquiring the fellowship of the Royal College of Surgeons or the membership of the Royal College of Physicians. For those wishing to pursue a career in hospital medicine further training and experience are necessary.

Because specialist qualifications have a legal meaning within social security systems the training programme leading to them in many countries is also statutory. 
Authority thus rests with governments, though the system is normally operated by medical bodies. This is in marked contrast to the United Kingdom, where medical bodies have almost complete freedom to determine the duration and content of training.

Minimum training times in the community are set out in the table. In most countries, but not in the United Kingdom, a single programme provides the trainee with the complete training, which may involve rotation between departments but rarely between hospitals. The United Kingdom and France are the only countries in which the number of programmes is related to the anticipated need for specialists. Other countries are moving in this direction but, in general, there is a considerable overproduction of specialists.

Duration of specialist training in the European Community in a range of specialties ${ }^{\star}$

\begin{tabular}{lcc}
\hline & \multicolumn{2}{c}{ Years } \\
\cline { 2 - 3 } Specialty & Minimum & Actual range \\
\hline Anaesthetics & 3 & $3-6$ \\
General surgery & 5 & $5-6$ \\
Orthopaedics & 5 & $5-6$ \\
Ophthalmology & 3 & $3-4$ \\
Obstetrics and gynaecology & 4 & $4-6$ \\
Internal medicine & 5 & $5-6$ \\
Paediatrics & 4 & $4-5$ \\
Psychiatry & 4 & $4-5 \cdot 5$ \\
\hline
\end{tabular}

${ }^{\star}$ Excludes United Kingdom and Republic of Ireland.

Entry to training is by a competitive grading examination in France and Spain. Elsewhere, trainees have to apply for posts and there is considerable competition. There is good evidence in Germany that some trainees are working unpaid in the hope of obtaining a post when one becomes vacant, and in several countries trainees may have to wait for several years before being accepted.

Training is normally provided in paid posts involving clinical responsibility under supervision but this is still not the case in Italy, where specialist training is conceived as a taught course in a university. Because the number of trainees is often large, practical experience may be slight. In Greece the official ratio of one trainee for every three beds is not universally maintained. Most countries have a list of recognised trainers or institutions, often laying down criteria for such recognition, but regular inspection of training posts occurs only in the United Kingdom and the Netherlands. Paid study leave is exceptional.

Satisfactory completion of the programme is normally attested by the trainer, though Belgium and Luxemburg also require trainees to present log books of their experience. There is an exit examination in Germany, Italy, and Greece.

\section{Training general practitioners}

In the United Kingdom general practice is the only medical discipline in which completion of a specific training is a legal requirement. Similar requirements exist in Denmark, the Netherlands, and France, while voluntary training schemes exist in several other countries. As the result of a 1986 directive such training will become mandatory throughout the community for doctors wishing to establish themselves in general medical practice after 31 December $1994 .{ }^{2}$ The directive requires at least one year of training in hospital posts and one year in a recognised practice.

This directive represents a genuine advance in training standards but several countries are experiencing difficulties with its implementation. Because of the intense competition for training posts in hospitals it has not been possible to reserve a sufficient number for those intending a career in general practice, and not all governments have been prepared to fund the general practice component. The Union Européen des Médecins Omnipraticiens, which represents general practitioners, believes that the training should, in any case, be of three years' duration. These problems remain to be overcome.

\section{Keeping up to date}

Throughout Europe specialists have long been involved in continuing medical education by means of specialist societies and journals and through contact with colleagues and trainees. Until recently general practitioners have been much more isolated and lacked educational opportunities. The ethical duty of both groups to involve themselves in continuing education has been recognised by their representative organisations, though any form of compulsion has been stoutly rejected.

Provision for continuing medical education has improved in the past decade. Several countries have legislated for its establishment, and others have introduced voluntary machinery. Italy is the only country in which participation is mandatory and backed by financial sanctions, but no provision for the necessary courses has been made.

\section{Advisory Committee on Medical Training}

The first two medical directives were accompanied by a third establishing the Advisory Committee on Medical Training within the European Commission "to help ensure a comparably demanding standard of training in (all member states of) the community." This body, comprising nominated experts drawn from the competent authorities, the universities, and the profession in equal numbers, has published three reports on the problems of specialist training. Some of its recommendations are set out in the box..$^{46}$

Sadly, these recommendations have not been widely implemented, and the European Commission has not been prepared to bring them forward in the form of new directives. A major obstacle to progress has been the lack of an educational infrastructure in several countries, where even the requirements of the existing directives may not be fulfilled in their entirety. Where training is largely a government rather than a professional responsibility, as in Greece, or wholly in the hands of the universities, as in Italy, doctors have not been able to bring about changes which many see as desirable.

In 1987 the Permanent Working Group of European Junior Hospital Doctors found that the advisory committee's recommendations were not fulfilled in their entirety in any member state. ${ }^{7}$ Particularly

Principal recommendations of the Advisory Committee on Medical Training, 1978, 1982, and 1985:

- Each state should have a competent authority to determine standards, inspect and recognise training centres, coordinate basic with specialist training, award certificates attesting legal qualification, and establish relations with corresponding bodies in other member states

- Trainee numbers must be related to training facilities and to the future need for specialists

- Remunerated, full time training with a service element is the norm

- Trainees must progressively assume a greater degree of independent responsibility as their skill and experience grow

- Training should proceed via a common trunk from the general to the more specialised. 
common were the absence of any system for inspection of training posts, lack of regulation of trainee numbers, scarcity of part time training, and inadequate supervision of trainees. The permanent working group adopted a policy statement on postgraduate medical education in 1988, the first such document to have been written by trainees, addressing educational issues which had not been dealt with by the advisory committee (box). Although well received and forwarded to the commission by the Standing Committee of Doctors of the EC, this document seems destined to have even less effect than its predecessors.

\section{Future prospects}

Standards of medical training, at both basic and specialist levels, remain variable across the community. Some of this variability is inevitable and perhaps desirable, given the different historical, social, and cultural influences which shape training systems, but some is due to political inertia, weak government, and lack of investment. Poor standards of training, combined with the overproduction of doctors referred to in the article published on 14 December ( $p$ 1534), undermine the principle of a free market as well as threatening standards of patient care.

There is thus a case for reviewing the medical directives and strengthening their educational provisions. Such a move would require a lead from the commission, which has repeatedly stated that it does not seek to intervene in the funding or administration of national health care systems. Commissioner Papandreou recently indicated that the commission was seeking a greater role in the areas of prevention, care, and medical assistance and was setting up an informal health committee. Whether this might lead eventually to the setting up of a directorate for health and greater interest on the part of the commission in medical training remains to be seen but, in the short term, new measures do not seem likely.

Improvements in training are more likely to result from national initiatives and from the collaborative efforts of European medical bodies. Perhaps the most promising of these is the recent decision of the Union Européen des Médecins Specialistes, through its monospecialty sections, to establish European boards, with the aim of harmonising specialist training. The boards will set training standards, inspect and recognise training programmes, and award certificates to those who complete training in a recognised centre. Because they will be part of the existing representative framework these boards are likely to be more credible and more effective than freestanding European colleges, which have also been proposed.

The other major influence for good is free migration.
Principal recommendations of the Permanent Working Group of European Junior Hospital Doctors, adopted 1988:

- The recommendations of the Advisory Committee on Medical Training should be supported and implemented

- Each trainee should at all times have a clearly identified trainer with defined responsibilities

- Training should include practical and theoretical instruction, private study and research, regular critical scrutiny with unambiguous feedback, and career guidance

- Trainers should receive training in educational methods and guidance on the fulfilment of their task

- Training posts should be inspected by the training authorities at least every five years

- The quality of training, rather than an exit examination, should be the means to achieving high standards, since examinations cannot test the full range of skills and attributes required in a specialist.

The number of doctors taking advantage of this is small, though substantial numbers are now coming to the United Kingdom, but Europe offers an unrivalled range of medical experience and an opportunity for the crossfertilisation of ideas. Sadly, migration for educational purposes has been hampered by the demand for posts generated by unemployment while exchange schemes have proved difficult to set up because of unequal standards of training, language barriers, and administrative complexity.

It is inevitable that training standards in Europe will converge, but they start from a point of great diversity and progress is likely to be slow. The United Kingdom has the advantage of a strong tradition of clinical teaching, a well established infrastructure, and an autonomous medical profession. It has much to offer to its partners in the community.

Council directives of 16 June 1975. 75/362/EEC and 75/363/EEC. Official fournal of the European Communities 1975; L167:1-16.

2 Council directive of 15 September 1986 on specific training in general medical practice. 86/457/EEC. Official Journal of the European Communities 1986;L267:26-8

3 Council directive of 15 June 1975 setting up an advisory committee on medical training. 75/364/EEC. Official fournal of the European Communities 1975;L167:17-8.

4 Advisory Committee on Medical Training. Report and recommendations on the general problems of specialist training. Brussels: Commission of the European Communities, 1978.

5 Advisory Committee on Medical Training. Second report and recommendations on the training of specialists. Brussels: Commission of the European Communities, 1983

6 Advisory Committee on Medical Training. Third report and recommendation of the conditions for specialist training. Brussels: Commission of the European Communities, 1986.

7 Brearley S, Beuzart S, Gredal J, Suntinger A, Gentleman D. Permanent Working Group of European Junior Hospital Doctors. Policy statement on postgraduate medical education. Med Educ 1989;23:339-47.

\section{ANY QUESTIONS}

The datasheet on Synacthen Depot (tetracosactrin) warns about anaphylactic shock. Does the risk of anaphylaxis remain after prolonged treatment with the drug?

The major risks of using tetracosactrin are allergic reactions. Two deaths have been reported in patients in whom treatment had been continued after a mild reaction had occurred with an earlier dose, and serious reactions have also occurred in patients who have had no previous reactions. Self injection is not advised. Therefore, tetracosactrin should be given only under medical supervision; it is recommended that the patient should be kept under observation for at least 30 minutes after the injection. Rarely, the benzyl alcohol in Synacthen Depot may provoke a hypersensitivity reaction. - T E T WEST, consultant physician, Telford, Shropshire

What is the exact origin of the peculiar letter $R$ which precedes all prescriptions? I know that it is said to be $R$ for recipe from the Latin recipio = I take (back), but it is the exact format of a Greek (?) $R$ with a stroke across it that puzzles me.

As the writer says, $\mathrm{R}$, the commonly used symbol for a prescription, is thought to be shorthand for "recipe." It does in fact have a much older provenance. It is a corruption of the Egyptian hieroglyph for the eye of Horus, and presumably can be found on documents such as the Ebers papyrus which show prescriptions, though I have not had an opportunity to confirm this. - ALEX PATON, honorary physician, Oxford 